\title{
5. Global earnings disparities in remote platform work: liabilities of origin? ${ }^{1}$
}

\section{Vili Lehdonvirta, Isis Hjorth, Helena Barnard and Mark Graham}

It's much easier getting jobs when you're not from Kenya. If I could change anything, I'd change people's perceptions. It feels demoralizing that people think that you're unskilled if you're from the third world. Third-world people are only offered low-skilled jobs. [Male, 27, Nairobi]

Online labour platforms are websites and apps that mediate between buyers and sellers of remotely deliverable knowledge work, such as software development, graphic design, writing, and data labeling (Horton, 2010). Online labour platforms or different subsets of them are also referred to as online gig platforms, freelancing platforms, outsourcing platforms, and microwork platforms. Regardless of what we think about the job quality (Wood et al., 2018) and income security (Lehdonvirta, 2018) of the kind of work that online labour platforms often provide, they are clearly opening up new opportunities for people in regions where other opportunities are scarce (Ghani et al., 2014). The opportunities they open up are welcomed especially by people with skills gained through experience or education, but with few avenues to apply those skills locally (Braesemann et al., 2020). This has led to visions of a global marketplace where geography no longer matters, and instead what counts is the individual and their skills (Kuek et al., 2015). But such visions may be going too far. Digital technologies can do much to bridge physical distance, and at the same time be less effective in overcoming other gaps. In this chapter we investigate ways in which location continues to matter for success even in digitally mediated work, using statistical analysis of platform transaction records supplemented with interview data.

To frame our investigation, let us start with the term "liabilities of origin," a term used in international business scholarship to refer to the special challenges that companies from emerging economies face as they attempt to compete in international markets (Pant \& Ramachandran, 2012; Ramachandran \& Pant, 2010). Thanks to the liberalization of international 
trade, global markets in many industries are now in principle open for companies from almost any country. Yet certain challenges continue to hold back companies specifically from less economically developed countries. Some of these challenges stem from the companies' home country contexts. For instance, education systems in less developed countries can be weak and fragmentary, leading to a dearth of skilled graduates who could help the business produce high-quality outputs and be internationally competitive.

Other challenges stem from the host country context, that is, the customer's or client's side. In particular, international business scholars highlight "negative attributions" that customers in a particular country may attach to firms from emerging economies (Ramachandran \& Pant, 2010). Studies in international marketing show that customers are often biased against products and services from marginalized countries, assuming them to be inferior in quality regardless of whether that is true in a particular instance or not (Verlegh \& Steenkamp, 1999) and being less willing to pay for them (Koschate-Fischer et al., 2012). This has been found to apply also in electronic commerce (Bracamonte \& Okada, 2015). Due to liabilities of origin such as these, firms originating in emerging economy countries are disadvantaged in international markets relative to their peers from other countries, even when they enjoy broadly the same level of market access in legal terms.

While the term liabilities of origin was originally coined to describe challenges faced by emerging-economy firms, similar liabilities linked with the country of origin also seem likely to hold back individual contractors offering services through online labour platforms. Platforms have done much to open up international market access for these contractors. Small emerging-economy firms rely mostly on personal networks to reach foreign clients (Ciravegna et al., 2014; Musteen et al., 2014), but few people in emerging economies have such international personal contacts. Platforms that bring together supply and demand across borders and provide tools for the two sides to communicate and to an extent trust each other are thus genuinely changing market access (Lehdonvirta et al., 2019; Braesemann et al., 2020). But this does not necessarily mean that they compete on an equal footing with contractors from high-income countries. Liabilities of origin stemming from both the home country context (e.g. poor-quality education) and the host country context (e.g. negative assumptions about quality) are possible. Moreover, when emerging economy firms struggle to navigate the global economy, they have a fairly substantial resource base that they can draw on for support and advice. Individuals engaging with a global marketplace via the Internet lack not only institutional protections but typically also the kind of resources that firms can draw on.

In the following sections, we analyze six months of transactions from a leading online freelancing platform to find out how the country of origin shapes online workers' experiences and earnings. The quantitative analyses 
are motivated and illustrated with salient quotes from face-to-face interviews conducted with online contractors in Southeast Asia (Philippines, Vietnam, Malaysia) and sub-Saharan Africa (Kenya, Nigeria, South Africa). Both data sets stem from a multi-year investigation of online labour platforms in emerging-economy countries. Different subsets of the data have previously been examined in articles such as Graham et al. (2017), Wood et al. (2018), and Lehdonvirta et al. (2019).

To ensure that we are comparing apples with apples, in this chapter we focus our quantitative analyses on projects categorized as writing work. We chose writing because it was what many of our interview informants were doing, it is relatively commodified in that the variation in rates is limited, it requires no formal qualifications, it is supplied by contractors from countries around the world, and it exists in large numbers in the records (34,352 projects in total). Also, since stereotypes of foreign countries vary across the world, we focused on U.S. and Canadian buyers. We chose these two countries because their combined market share is very high in global outsourcing in general and the platform economy in particular.

The structure of this marketplace and of online contracting in general calls for a multi-level study design: our smallest unit of analysis is an individual project; each project belongs to a contractor, and each contractor comes from a country. We are interested in whether the rates paid for a project vary depending on the contractor's country, and what country characteristics might account for this variance. These levels and the main variables of interest are depicted in Figure 5.1. A detailed description of the data and methodology is included at the end of the chapter.

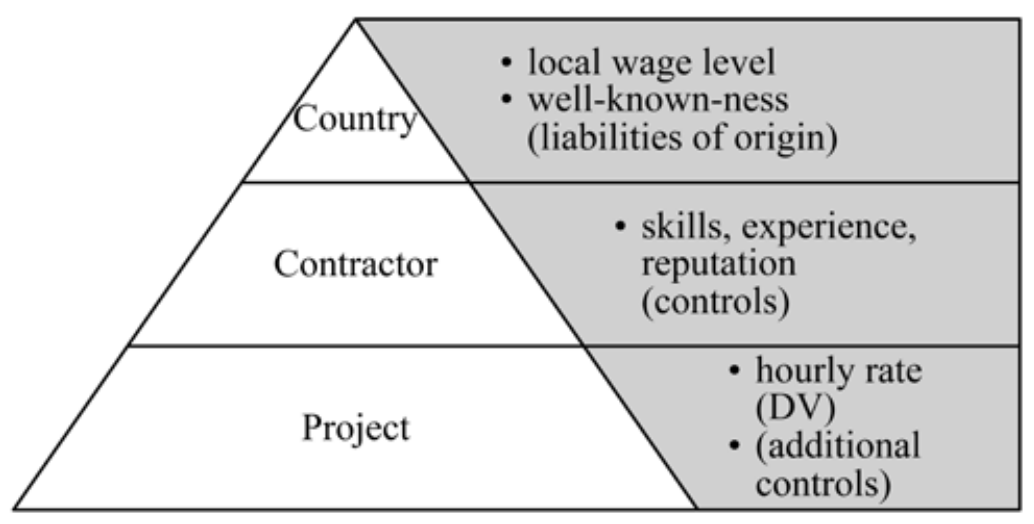

Figure $5.1 \quad$ Three-level design, levels, and variables 


\section{GLOBAL EARNINGS DISPARITIES IN ONLINE WORK}

Let us start our analysis of the transaction records by examining whether there are any obvious differences between how much workers from different countries are earning on the platform. Figure 5.2 shows how much workers from different countries earned per one hour of writing work on the platform. The figure reveals some familiar patterns. First, it suggests that there are significant earnings disparities between countries. For instance, with a rate of $\$ 4.26$ per hour, the mean Kenyan earned only a third of what a mean U.S.-based worker was earning. Second, it shows that the earnings disparities are structured along a familiar high-income vs. lower-income country continuum. The four top-earning countries on the platform are all classified as high-income countries according to the World Bank, while the bottom five are classified as lower middle-income countries. The middle ground in platform earnings is occupied by a mix of middle-income countries (we will also use the terms emerging economy and lower-income country to refer to countries that are not classified as high-income countries).

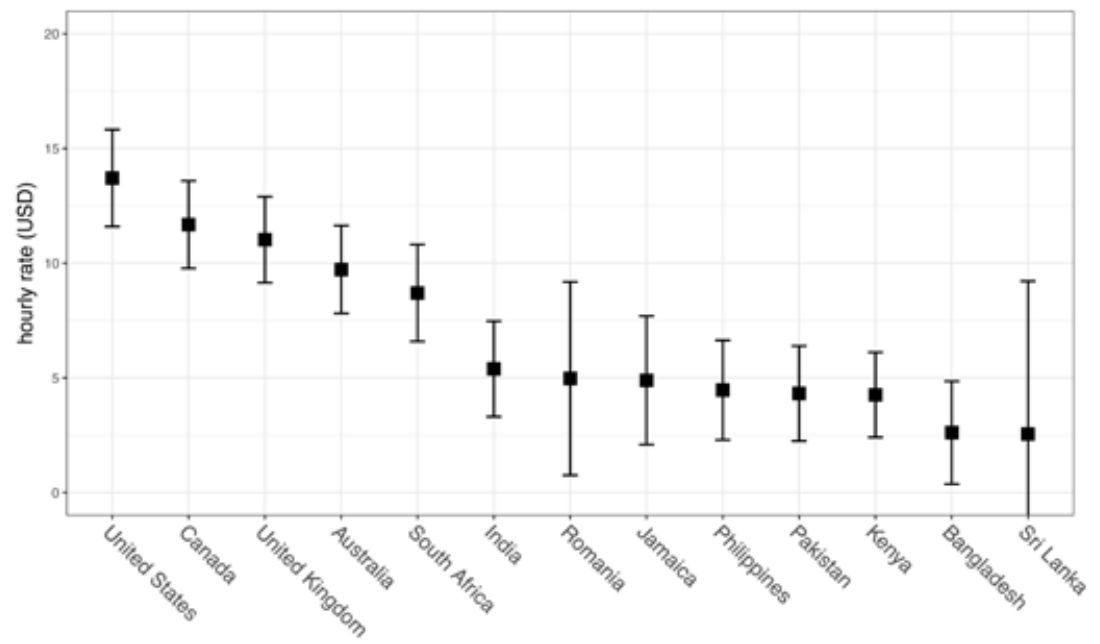

Figure 5.2 Predicted pay rate by country in USD (residual standard errors in bars

The values in Figure 5.2 are geometric means rather than the more familiar arithmetic means ("averages"). Geometric means are less affected by outliers, so they give a more reasonable idea of what a "typical" worker might 
be earning. They are lower than average pay rates: for instance, U.S.-based writers on average earned $\$ 18.61$ per hour, but their geometric mean earnings were just $\$ 13.71$ per hour. This is because a handful of superstars pushed the average up, with one writer earning as much as $\$ 175$ per hour in one project. At the same time, a long tail of U.S.-based novice online writers was charging next to nothing to try to break into the market. The geometric means in our case are very close to median pay rates, so they can be thought of roughly as what a "middle of the road" worker is earning. For brevity, we will refer to them simply as means.

We can also compute a "within-country correlation coefficient" for the model underlying Figure 5.2. This statistic tells us how much of the observed variation in workers' earnings rates on the platform is attributable to unexplained variation between countries rather than to variation between individuals or projects. This figure is approximately 35 percent - that is, 35 percent of the workers' pay rates seems to be determined by their countries of origin.

\section{IMPACT OF CONTRACTOR QUALITY}

To what extent are the stark rate differences that we found between countries explained by differences in human capital, that is the skills or quality of the labour supplied to the market? The United States has a better education system and various other institutional advantages over Bangladesh, so U.S.-based contractors might be expected to be more competent on average than workers based in Bangladesh. Though we don't have data on the workers' educational and other qualifications, we do have some quite straightforward measures of contractor competence. We know how many skill tests each contractor has successfully completed on the platform. These are voluntary computer-administered tests that assess the contractor's abilities in areas such as language skills, important software packages, and general business and communication skills. We also know how many projects they have previously completed on the platform. To the extent that experience translates into competence, this is another partial indicator of the contractor's competence. Finally, we know the average feedback rating that the contractor has received from previous clients. Taken together, these three imperfect measures can be used to provide a reasonable picture of contractor competence. Interview 
participants certainly felt that these measures were important determinants of pay on the platform:

Once you're able to take a test for that skill you've acquired, you're telling your potential clients that I'm capable of doing this stuff: "Hey you can go see my profile; I'm capable of doing that." [Male, 23, Abuja]

I ask for more money now than I asked for five years ago. I have more experience, and $[\ldots]$ many good feedbacks and clients can trust me on projects. [Male, 31, Ho Chi Minh City]

Table 5.1 presents the country means of the three contractor competence characteristics: experience, reputation, and skills. The countries are presented in the order of the sum of these three characteristics, which can be thought of as a simple human capital index for the online contractors from that country. Contrary to expectation, Bangladesh ranks slightly above the United States in this index. In fact, most of the lower-income countries in the list rank higher than the high-income countries with better education systems and other institutional factors. This counter-intuitive finding can be explained by the fact that highly competent workers in high-income areas are likely to have many opportunities in their local labour markets, with little need to turn to online labour markets for work. In contrast, highly competent workers in lower-income areas may find better opportunities online than in their local markets (Braesemann et al., 2020). Contractors from lower-income countries may also be investing more time into the skill tests if the opportunity cost of their time is lower.

Table $5.1 \quad$ Contractor quality characteristics, averages by country

\begin{tabular}{l|l|l|l|l}
\hline & Experience & \multicolumn{1}{l}{ Reputation } & \multicolumn{1}{l}{ Skills } & \multicolumn{1}{l}{ Sum } \\
\hline South Africa & 4.06 & 4.63 & 8.55 & 17.25 \\
\hline Romania & 3.43 & 4.90 & 6.89 & 15.21 \\
\hline India & 3.51 & 4.54 & 5.13 & 13.18 \\
\hline Philippines & 3.52 & 4.57 & 4.79 & 12.88 \\
\hline Pakistan & 3.57 & 4.68 & 4.48 & 12.73 \\
\hline Bangladesh & 3.37 & 4.53 & 4.70 & 12.60 \\
\hline United States & 3.34 & 4.63 & 4.02 & 11.99 \\
\hline Canada & 3.32 & 4.52 & 4.12 & 11.97 \\
\hline Kenya & 3.55 & 4.39 & 3.80 & 11.75 \\
\hline United Kingdom & 3.29 & 4.63 & 3.30 & 11.22 \\
\hline Sri Lanka & 3.58 & 4.70 & 2.43 & 10.71 \\
\hline Australia & 2.94 & 4.63 & 2.94 & 10.51 \\
\hline Jamaica & 2.80 & 4.56 & 2.00 & 9.36 \\
\hline
\end{tabular}




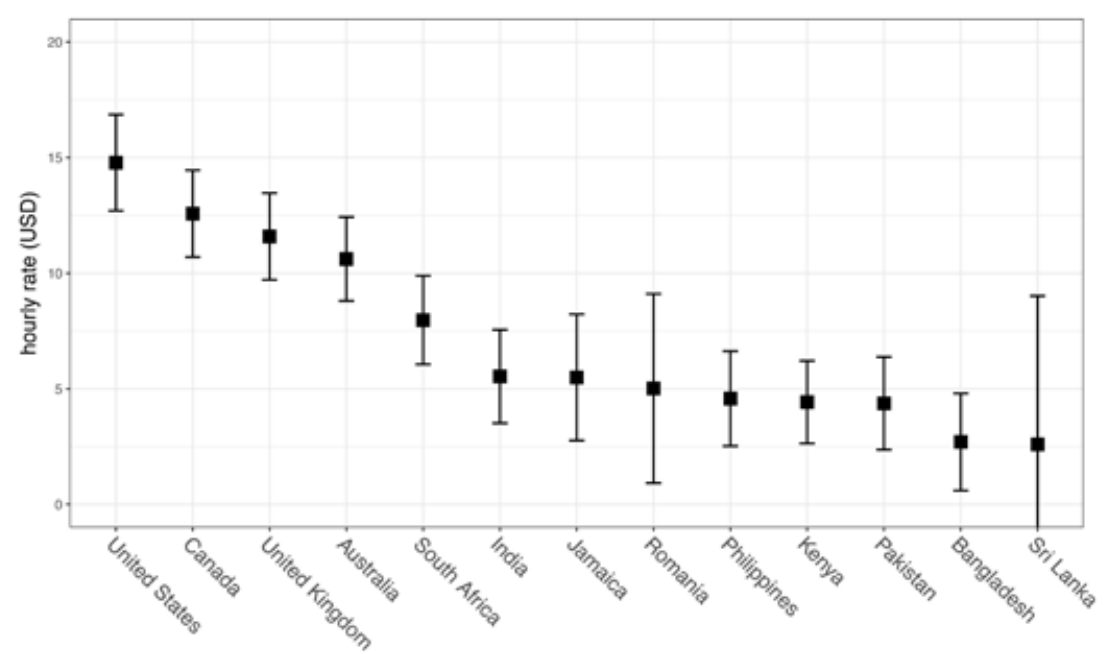

Figure 5.3 Predicted pay rate by country in USD, controlling for worker experience, reputation, and skill tests (residual standard errors in bars)

Although Table 5.1 already strongly suggests that differences in human capital are not going to explain why emerging economy workers earn less online, we can examine the link formally with a multi-level mixed-effects regression model. The variable being explained is the hourly rate (log-transformed), and the contractor quality characteristics are entered into the model as control variables. The resulting model allows us to predict how much workers in different countries would earn in a hypothetical world where all workers had exactly the same competence characteristics. The results are shown in Figure 5.3. Not much changes: the country mean earnings remain very close to those presented in Figure 5.2. Adding the time zone difference between the worker and the client to the model as an additional control variable likewise has no practically significant effect. The within-country correlation coefficient of the model increases slightly to 37 percent.

\section{IMPACT OF LOCAL OPPORTUNITIES}

Our analysis thus far shows that over a third of the variation in hourly rates is attributable to the workers' countries of origin, and that these country-level disparities don't seem to be explained by differences in human capital or time zones. The differences persist despite many lower-income countries supplying at least as good or more competent workers to the platform than many 
high-income countries, according to the available measures. Another possible explanation for the pay rate differences can be found in the combined effects of local wage levels and competition. Workers lacking well-paid opportunities available in the local labour market are presumably willing to accept online projects at lower rates. In contrast, workers whose local job market provides many well-paid opportunities will presumably find only higher-paying online projects worth accepting. Indeed, interview participants in many cases compared their online rates to what they could earn on the local labour market:

I'm going to compare [the pay offer] with my daily - because that's what I can see myself working for the entire day, $\$ 30$ [...] So that's my whole day's work, more or less the same salary [as] with my call center job. [Female, early 30s, Manila]

This intuition corresponds to the "reservation wage" model used in labour economics (Lippman \& McCall, 1976). The salience of reservation wages is influenced by the level of competition in the market (Manning, 2011). If there is little competition between contractors, then contractors can charge whatever the client is willing to pay, and their local wage level doesn't enter into the picture. But if competition is intense and results in bidding wars, then the best alternative option in each contractors' local labour market determines the minimum rate at which it still makes sense for them to bid for a project online. We know that competition on platforms can be very intense, as they extend access to many workers around the world. Although demand-side entry barriers are also diminished (by for instance allowing work to be purchased in smaller chunks), the evidence suggests that there is currently more supply than demand on global platforms (Kuek et al., 2015; Graham et al., 2017), though this does vary by type of work (Kässi \& Lehdonvirta, 2018). Differences in local wage levels together with intense competition could thus explain why contractors from lower-income countries such as the Philippines, Kenya, and Pakistan end up working at significantly lower rates than contractors from high-income countries such as the United States, the United Kingdom, and Canada.

We can examine this hypothesis by entering the local wage level as an additional control variable to our model predicting contractor pay. The results are depicted in Figure 5.4. This time the impact is significant. When the effect of the local wage levels is eliminated, the country differences in contractors' pay rates become less pronounced, and, more importantly, the order of the countries changes - the predicted top-earners are now contractors from India and Pakistan! The within-country correlation coefficient falls from 37 to 14 percent. In other words, a large share of the variation in the rates that contractors earn online seems to be attributable to differences in their local wage levels. Contractors from countries with lower wage levels are willing to take 


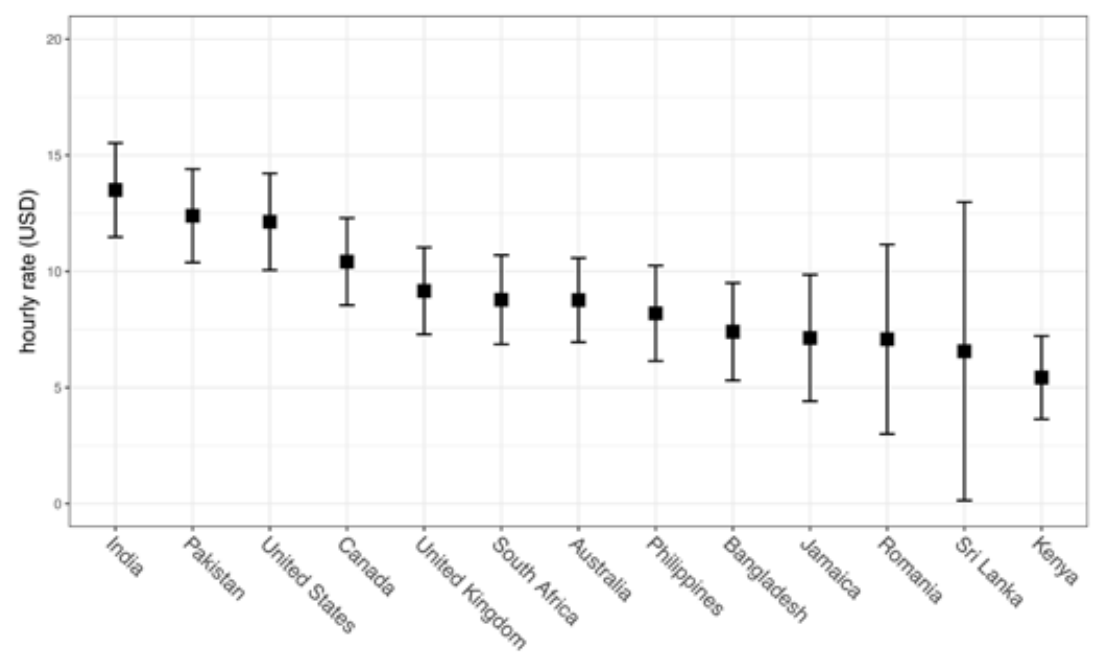

Figure $5.4 \quad$ Predicted pay rate by country in USD, controlling for worker experience, reputation, skill tests, time difference, and local wage level (residual standard errors in bars)

up projects that pay lower rates. Contractors from high-income countries are more likely to only accept projects that pay a higher rate. Such projects occur perhaps because the client is in a hurry and cannot wait for lower bids, because they need a very particular skill set that the contractor happens to have, or because they simply wish to pay a higher rate for compliance or ethical reasons.

Nevertheless, even when the impact of the local wage level is controlled, most lower-income countries still rank below the high-income countries in terms of platform pay rates. Fourteen percent of the variation in pay rates is still attributable to unexplained country-level differences. Can this remaining impact of geography somehow be explained?

\section{IMPACT OF CLIENT PERCEPTIONS}

So far we have examined how factors stemming from the contractor's home country context influence pay rates and help to explain global pay disparities. As a final step, let us shift our attention to how the client country context may be generating or supporting global pay disparities. It is well established in the international marketing literature that clients' or customers' perceptions of foreign countries influence their perceptions of the quality of goods or services from those countries (Johansson et al., 1985; Verlegh \& Steenkamp, 1999), and consequently their willingness to pay them (Laroche et al., 2005; 
Koschate-Fischer et al., 2012). This is particularly the case when the good or service lacks a strong brand or reputation of its own (Maheswaran, 1994). It seems highly plausible that such perceptions might be influencing international clients' willingness to pay for platform-mediated labour as well. Many interview participants certainly felt that this was the case, as illustrated by this quote:

This perception [of clients] that third world countries are not good. It hurts. It's very demoralizing. The perception, I really hate it because in this country we've come up with some of the most innovative ideas and if people in oDesk would just utilize such talents, they're here. [Male, 27, Nairobi]

In the international marketing literature, country images are typically conceptualized in terms of the associations attached to them (e.g. German cars), their valence (from positive to negative), and their strength (from strong to no image at all) (Shimp et al., 1993). These are typically measured with surveys. Since we do not have suitable survey data available, we adopt a more innovative approach: we measure the strength of a country's image, its "well-known-ness," with a proxy developed from Internet search volume data. Search volume data are increasingly used in social and economic research to measure aggregate human behaviors and attitudes (Choi \& Varian, 2012; Preis et al., 2013), including racial attitudes (Stephens-Davidowitz, 2014). Using the Google Trends database, we captured the relative frequency of each of the countries among Google search queries performed in the United States. The resulting variable shows that Americans are most likely to type United States into their search boxes (relative frequency 480) and least likely to type Sri Lanka (4).

This approach has advantages and disadvantages. A country's relative popularity in searches is admittedly an imperfect proxy for how well-known the country is. But a significant advantage of this measure is that it is observational as opposed to self-reported, as honest survey responses on a person's knowledge and ignorance are difficult to elicit. The main drawback of this approach is that we are only measuring the strength of the country image, not its valence. Yet there are good reasons to expect that simply how well-known as opposed to obscure a country is - how familiar clients are with a country - is likely to affect clients' assessments of contractors from that country. Studies in both labour economics (Arrow, 1998) and social psychology (Fiske, 1998) suggest that familiarity diminishes the salience of (negative) stereotypes, and experiments in behavioral economics suggest that simply being able to recall a (country's) name from previous memory positively influences clients' assessments of it (Tversky \& Kahneman, 1974). This intuition was articulated by an 
online worker, a woman from Lesotho, a small neighbor of South Africa. She explained:

I am actually from Lesotho, not South Africa. I find it's easier to put South Africa on my profile than to put Lesotho, because not a lot of people know where it is and it's just easy for people to have a point of reference.

Entering our measure of worker home country well-known-ness into the model has a dramatic effect (Figure 5.5). When country differences in well-known-ness are eliminated, the remaining country differences in platform pay rates are slashed, and the order of the countries is completely revamped. The predicted earnings rates range from $\$ 10.08$ (Kenya) to $\$ 15.41$ (Pakistan), and United States is third from the bottom, with a predicted mean rate of $\$ 10.91$. The within-country correlation coefficient falls to just 5 percent, which means that our model is now able to account for almost all of the causes of country-level disparities in platform pay rates - the most important of which turned out to be differences in local wage levels and differences in client perceptions of the contractor home country. The $\mathrm{R}^{2}$ of the model is 43 percent, compared to 30 percent for the previous model without country well-known-ness.

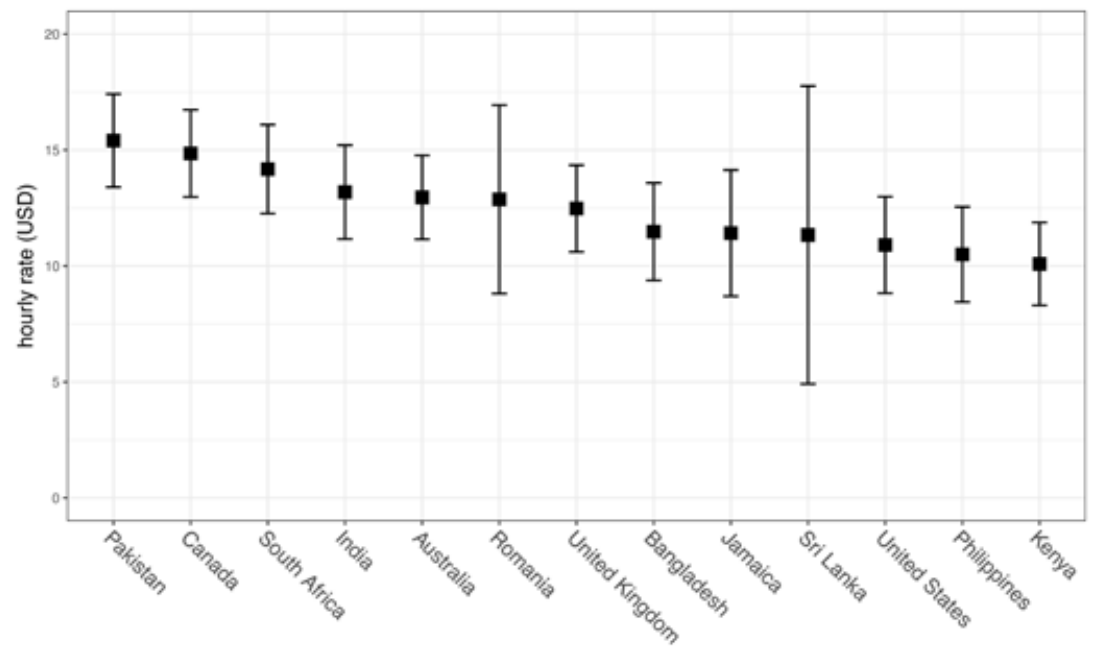

Figure 5.5 Predicted pay rate by country in USD, controlling for worker experience, reputation, skill tests, time difference, local wage level, and country well-known-ness (residual standard errors in bars) 


\section{DISCUSSION}

In this chapter we examined how workers' geographic origin shapes their experience and pay rates in the platform economy. The question is brought to the fore by new technologies that expand the scope of labour markets from local to transnational. To frame the question, we adopted the concept of "liabilities of origin" (Ramachandran \& Pant, 2010) from international business scholarship. As expected, our quantitative findings showed that there were large country-level differences in the rates that contractors earned online. Following the liabilities of origin approach, we examined how both the home country context and the client country context resulted in liabilities that disadvantage workers from emerging economy countries compared to their peers from high-income countries. We will discuss the implications and limitations of each of our findings in turn below.

\section{Institutions and Human Capital}

One of the ways in which the home country context is seen to disadvantage actors from emerging economy countries is that its institutions are weak or underdeveloped (Pant \& Ramachandran, 2012). Some institutions act as enablers that determine whether contractors can access the online market in the first place; others influence how much human capital they bring to the market (Kuek et al., 2015). Our findings concern those individuals who do have access to the market. Somewhat contrary to expectations, our findings suggested that contractors from lower-income countries brought more human capital to the market than contractors from high-income countries, measured in terms of online contracting experience, reputation score, and number of skill tests completed (Table 5.1). This finding can be explained by a lack of opportunities in the local market in lower-income countries. High skill test counts in lower-income countries could also reflect an increased need to signal quality to counter buyer-side biases (Lehdonvirta et al., 2019). In any case, observed country differences in rates were clearly not driven by contractors from lower-income countries having less demonstrable experience, possessing fewer proven skills, or delivering lower-rated work; almost the opposite was the case.

This finding may have important implications to development policy. The UNDP's 2015 Human Development Report, with its focus on "rethinking work," centrally notes that "there has never been a worse time to be a worker with only ordinary skills and abilities" and that "this new world of work puts a high premium on workers with skills and qualifications in science and technology" (UNDP, 2015: 10). While that is undoubtedly true, our findings 
make it clear that it is only part of the story. Differences in human capital did not explain country differences in rates observed in the online labour market; this suggests that investments in evening out human capital differences may not succeed in evening out earnings gaps. Admittedly there are likely to be aspects of human capital or worker quality that our variables failed to capture, but the finding nevertheless strongly indicates that we should consider other explanations as well.

\section{Local Markets vs. Global Opportunities}

A much stronger way of explaining country disparities in platform pay rates turned out to be the impact of local wage levels. Workers in areas with high local wages performed online projects that paid more, while workers whose local wage levels were low accepted lower-paying online projects on the mean. This is easy to understand through the reservation wage model (Lippman \& McCall, 1976): if the worker has a better-paying option on the local market, why accept a lower-paying task online? This means that workers from emerging economies don't necessarily do fewer high-paid projects, but that their mean earnings are pushed down by the fact that they also accept lower-paying tasks.

Another possible interpretation is that workers from high-income countries have some special skills, not captured by our contractor quality variables, for which reason they are more likely to be hired into more demanding projects. We tried to limit this possibility by focusing our analysis on projects categorized as writing work, as these are more homogeneous than for instance software development projects, which vary hugely in terms of the skills required. In Lehdonvirta et al. (2019) we performed similar analyses on projects categorized as graphic design work and with additional contractor competence control variables, with similar results. This supports our conclusion that workers with higher local wage levels simply self-select out of the lower-paying tasks. A positive implication from this for economic development is that if/when local wage levels in the world's marginalized regions grow, online contractors in these countries can be expected to shift toward higher-paying tasks as well. In the meanwhile, the reservation wage model suggests that any interventions that reduce the intensity of competition in online work - such as collective organizing (Wood et al., 2018) - should increase lower-income contractors' rates.

\section{Client Perceptions and Digital Media}

Turning to the client's side, we found that a measure of how well-known the contractor's home country was in the client's country was able to explain 
most of the remaining country-level disparities in platform earnings rates. A possible mechanism is that better-known countries are less susceptible to stereotyping (Fiske, 1998), or that familiar things are preferred over unfamiliar ones (Tversky \& Kahneman, 1974). As a consequence, contractors from less well-known countries are disadvantaged on the global market.

However, this interpretation should be treated only as tentative. Cross-country analyses associating one variable with another are inherently low-N, and many social and economic development indicators are mutually correlated due to being bound up in webs of causal relationships. Many other variables besides well-known-ness might have yielded similar effects, and we did not use experimental or econometric techniques to attempt to identify the causal factor. Having said that, three factors lend credibility to our interpretation of the result. First, the finding stands on two empirical legs: some of our qualitative interview data as well as quantitative analysis of transaction records suggested that buyers attributed more value to online contractors from well-known countries. Second, our quantitative measure of country well-known-ness has significant conceptual and empirical distance from the usual suite of mutually correlated development indicators (GDP, HDI, Internet penetration, etc.). For example, though India scores lower than the U.K. (55 vs. 60), it scores much higher than the more economically developed South Africa (9) and even Australia (34). That such a measure can help explain variation in an unrelated economic variable (hourly rate) is not obvious at face value. Third, the finding has simple and reasonable theoretical interpretations, as discussed above. Still, most social science phenomena are massively overdetermined; many causes contribute to an outcome. This effect, to the extent that we believe in it, should be seen as an example of what is probably a wider family of client-side geographic biases shaping the everyday experiences of online contractors.

A biased reception based on one's country of origin is of course a common phenomenon in conventional labour markets as well. Studies in many national labour markets show a wage gap between migrants and locals, only part of which can be explained by differences in skills and other worker characteristics (ILO, 2015). Studies attribute the unexplained variation to factors such as discrimination arising from prejudice or distrust (Solé \& Parella, 2003), perceived lower consumption needs and lack of representation in labour unions (ILO, 2015), and the difficulty of assessing foreign educational credentials (Barrett et al., 2012). Not all of these explanations may be applicable to remote platform work. Collective bargaining work appears next to non-existent so far (Wood et al., 2018), and the function of conventional educational credentials (which are practically unverifiable in the online context) is intended to be fulfilled by the platforms' own (verifiable) skill tests (Kässi \& Lehdonvirta, 2018), in which we saw that lower-income workers actually appear to be better qualified. 
Moreover, a significant difference between migrant labour and online contracting (or "virtual migration"; Horton, 2010) is that in the latter case the relationship is mediated by digital platforms, which influence what information is presented about the worker and how. We can draw on research in computer-mediated communication to understand some potential consequences of this to liabilities of origin. Levels of anonymity afforded by computer-mediated communication are known to contribute to depersonalization, that is a tendency of the participants to perceive each other as representatives of salient social categories rather than as individuals with idiosyncratic behaviors and needs (Lee, 2006; Postmes et al., 1998; Spears \& Postmes, 2015). By leaving out many other cues about a contractor's identity while prominently displaying their country of origin, platforms may inadvertently be inviting clients to relate to contractors through country stereotypes more strongly than they would otherwise do. It is noteworthy that in contrast to conventional outsourcing firms, the online contractor is a "micro-provider" who has no organizational affiliation that would act as the most salient social category instead of their country (Lehdonvirta et al., 2019). The liability of origin in online contracting thus differs subtly in mechanisms and perhaps also in magnitude from both firm-based liability of origin and the migrant wage penalty. An interesting implication from this conclusion is that platforms may be able to influence buyer-side biases by manipulating the range of information displayed about contractors. For example, displaying a greater variety of identity cues could make the country less salient and reduce the depersonalization effect. But for now, this remains speculation.

\section{CONCLUSION}

In place of visions of revolutionary change brought about by ICTs that remove all barriers, we inevitably find a more nuanced reality, where technology opens up new options but also perpetuates some old patterns and biases. Platforms clearly provide new opportunities in marginalized regions of the world where local opportunities are constrained. These opportunities benefit especially people with valuable skills that are hard to put to use in the local labour market. Online contractors from marginalized countries are not necessarily inferior at all in quality to online contractors from high-income countries, at least in occupations such as writing that do not depend on highly specialized training available only in higher-income countries. At the same time, they do suffer some liabilities of origin relative to their peers from high-income countries. These liabilities are in many ways similar to the disadvantages faced by emerging-economy firms seeking to break into international markets, or immigrant workers entering a new labour market, except for one notable difference 
- the role of the platform as the mediator of the exchanges and thus the shaper of the decision environment.

\section{DETAILED METHODOLOGY}

\section{Overall Approach and Interview Data}

Our overall empirical approach is an exploratory statistical analysis of data derived from records of transactions carried out on an online labour platform from March 1 to August 31, 2013. The transaction records were provided to us by a leading online labour platform company in an anonymized, privacy-protected form. The company did not wish to be identified by name. The platform facilitates the entire contracting relationship, from search and negotiation to supervision, delivery, billing, and post-project evaluation. It is an excellent context to study global online contract work, because it hosts clients and contractors from any country, and is among the largest such platforms.

The quantitative analyses are supplemented with quotes from face-to-face interviews with workers carried out in six countries between September 2014 and December 2015. In total, 107 workers were interviewed across Southeast Asia (in the Philippines, Vietnam, and Malaysia) and sub-Saharan Africa (in South Africa, Kenya, and Nigeria). The process of collecting the interviews is described in detail in the appendix of Lehdonvirta et al. (2019). For the purposes of this chapter, we selected quotes from these interviews that help to motivate and illustrate issues covered by the quantitative analyses. For more systematic analyses of this interview data, see e.g. Wood et al. (2018) and Wood et al. (2019).

\section{Multi-level Random Intercept Model}

The structure of the online labour market calls for a multi-level, nested study design, where projects belong to contractors, and contractors belong to countries (Figure 5.1). We are interested in whether the rates paid for a project vary depending on the contractor's country and, in particular, whether certain country characteristics (well-known-ness and local wage level) account for this variance. Besides the country-level variables of interest, we naturally also expect individual contractor characteristics such as skills and experience (that is, human capital or worker competence) to have a strong influence on the rates paid. Since these endowments may vary between countries, they must be included as control variables. The characteristics of different projects must likewise be controlled as far as possible. The resulting design can be expressed 
as the following three-level random intercept model (using the triple indexing notation of Snijders and Bosker, 1999):

$$
Y_{i j k}=\gamma_{000}+\sum_{n} \gamma_{n} x^{n}{ }_{. k}+\sum_{n} \beta_{n} x^{n}{ }_{. j k}+\sum_{n} \alpha_{n} x^{n}{ }_{i j k}+V_{00 k}+U_{0 j k}+R_{i j k},
$$

where $Y_{i j k}$ is the hourly rate paid in project $i$ to contractor $j$ belonging to country $k$. The term $\gamma_{000}$ is the main intercept. The term $\sum_{n} \gamma_{n} \mathrm{x}^{n}{ }_{. . k}$ refers to the country characteristics and their coefficients, and $\sum_{n} \beta_{n} \mathrm{x}^{n}{ }_{. j k}$ and $\sum_{n} \alpha_{n} \mathrm{x}^{n}{ }_{i j k}$ refer respectively to contractor and project-level characteristics and their coefficients. The last three terms are the country-, contractor-, and project-level random effects terms; residual variation in the dependent variable is decomposed into these different levels to address the question of how much contractors' countries influence the rates earned. Explanatory variables are not decomposed, as between-group effects are not assumed to differ from within-group effects.

\section{Data and Variables}

The full transaction records cover all 362,220 projects carried out on the platform from March 1 to August 31, 2013. Out of all the diverse types of projects contracted via the platform, we focused on one type of work: writing work, defined as projects categorized under "Blog \& Article Writing," "Creative Writing," "Copywriting," or "Technical Writing" in the platform's ontology. Hourly rates can vary by orders of magnitude between different types of work (from a mean of \$2.99 in "Data Entry" to \$38.10 in the "Legal" category) and addressing this statistically in our multi-level design would result in a complex and opaque model. Limiting ourselves to one type of work allows us to compare apples with apples when it comes to country differences. We chose writing because it was what many of our interview informants were doing, it is relatively commodified in that the variation in rates is limited, it requires no formal qualifications, it is supplied by contractors from countries around the world, and it exists in sufficient numbers in the records to facilitate multi-level analysis $(34,352$ projects in total).

To eliminate sources of variation that would be difficult or impossible to control otherwise, we applied two further selection criteria. First, only projects billed on an hourly basis were included ( 9,243 projects). The platform also supports fixed-payment projects but controlling project size becomes a problem 
in these. Second, only projects where the client is from the United States or Canada were included, to eliminate variation in buyer-side biases across different buyer countries (5,390 projects). We focus on U.S. and Canadian buyers because their combined market share is very high in global outsourcing in general and on this platform in particular. Finally, projects with an undefined or zero hourly rate and projects where no money was charged were pruned as artifacts $(5,256$ projects remaining). Countries whose contractors performed fewer than 20 projects in total were pruned to satisfy model assumptions (4,817 projects remaining, belonging to 3,078 contractors from 13 countries).

Table $5.2 \quad$ Levels, variables, and descriptive statistics

\begin{tabular}{|c|c|c|c|}
\hline & & $\begin{array}{l}\text { Mean (s.d.), } \\
\text { raw }\end{array}$ & $\begin{array}{l}\text { Mean (s.d.), } \\
\text { transformed }\end{array}$ \\
\hline Project & Rate (DV) & $11.01(10.93)$ & $1.99(0.98)$ \\
\hline$(n=4,817)$ & Time difference & $6.20(4.86)$ & \\
\hline Contractor & Experience & $62.08(82.76)$ & $3.42(1.32)$ \\
\hline \multirow[t]{2}{*}{$(n=3,078)$} & Reputation & $4.58(0.84)$ & $-1.95(1.55)$ \\
\hline & Skills & $4.40(5.81)$ & \\
\hline Country & Local wage level & $7.59(8.21)$ & $1.08(1.69)$ \\
\hline$(n=13)$ & Well-known-ness & $59.62(127.89)$ & $3.06(1.33)$ \\
\hline
\end{tabular}

Table 5.2 shows the variables used in the analysis and their descriptive statistics both in their raw form and after transformations were applied. Rate is the hourly rate paid to the project's contractor in U.S. dollars; as is common in studies of wages and earnings, it is right-skewed and entered into the model log-transformed. Time difference is measured as the absolute difference between the client's country's time zone and the contractor's country's time zone in hours; for countries spanning multiple time zones, an estimate of the country's center of population is used. Experience is measured as the number of projects the contractor has completed on the platform since joining the marketplace; it is right-skewed and entered into the model log-transformed. Reputation is measured as the contractor's mean feedback score from clients, on a scale from 0 to 5 . As it is left-skewed (many providers have close to 5-star ratings), it is reflected and log-transformed. Skills is measured as the number of computer-administered skill tests the worker has successfully taken on the platform and published on their profile. These tests are voluntary and measure such skills as typing, language proficiency, and office software use.

The local wage level variable represents the country's average hourly wage across all sectors. The variable is expressed in U.S. dollars, converted using exchange rates rather than PPP to correspond with the method a contractor 
would use to convert their local labour market wage to their online asking rate. For eight out of the 13 countries represented in the data set, it was possible to calculate this variable using the Occupation Wages around the World (OWW) database (Oostendorp, 2012). For Kenya, Pakistan, South Africa, Sri Lanka, and Jamaica, it was necessary to rely on separate ILO and national reports, resulting in potentially inconsistent methodologies. The most recent year for which wage data could be obtained across the countries was 2008, so the variable is somewhat out of date compared with the rest of our data set. Despite these limitations, the variable fulfills its function of capturing the main contours of the stark differences in wage levels across the countries in our data set, from Sri Lanka's $\$ 0.43$ to the United Kingdom's \$19.64 per hour.

The well-known-ness of a country was measured with a proxy developed from Internet search volume data. Using the Google Trends database, we captured the relative frequency of each of the 13 countries among Google search queries performed in the U.S. on June 1, 2013. The resulting variable shows that Americans are most likely to type United States into their search boxes (relative frequency 480) and least likely to type Sri Lanka (4). This approach has advantages and disadvantages compared with the survey methods used in most studies of country-of-origin effects (e.g. Bracamonte \& Okada, 2015). Search volume data cover the majority of the U.S. Internet user population instead of a small but possibly more targeted sample; in some studies this would be a problem, but in a study of online contracting, Internet users are a relevant population. The main drawback is that the resulting measure (country's relative popularity in searches) is an imperfect proxy for the construct of interest (how well-known a country is), which limits its validity. But a significant advantage is that the measure is observational as opposed to self-reported, which is likely to enhance its reliability, as honest survey responses on a person's knowledge and ignorance are difficult to elicit. All in all, we believe that this novel measure of country reputation is appropriate for this study and likely to have applications beyond the study as well.

We estimate model parameters using the restricted maximum likelihood method and assess mode fit using Nakagawa and Schielzeth's (2013) marginal (fixed effects only) and conditional (fixed and random) $\mathrm{R}^{2}$. The key statistic in this study is the intraclass correlation coefficient (ICC), which we use to examine how much of the variation in the dependent variable is due to variation between countries. Model parameters for all the models are presented in Table 5.3. Since our data covers all the writing work transacted over the platform during the study period rather than a probabilistic sample of it, inferential statistics such as p-values are not shown. All the results are statistically significant; we are instead concerned with assessing their practical significance. Generalizations beyond the data in the discussion section are inductive rather than statistical in nature. Our combination of qualitative and quantitative 
evidence from a key site in the field provides us with a good basis for cautious inductive generalization.

Table 5.3 Estimates for three-level random intercept models with $\log ($ rate) as the dependent variable

\begin{tabular}{|c|c|c|c|c|c|c|c|c|c|}
\hline \multirow[b]{2}{*}{ Fixed effects } & \multicolumn{2}{|c|}{ Null model } & \multicolumn{2}{|c|}{ Model 1} & \multicolumn{2}{|c|}{ Model 2} & \multicolumn{2}{|c|}{ Model 3} & \multirow{2}{*}{$\begin{array}{l}\text { Model } \\
4 \\
\text { Coef. }\end{array}$} \\
\hline & Coef. & S.E. & Coef. & S.E. & Coef. & S.E. & Coef. & S.E. & \\
\hline Intercept $\gamma_{000}$ & 1.777 & $(0.160)$ & 1.284 & $(0.165)$ & 1.273 & $(0.194)$ & 0.151 & $(0.327)$ & 0.241 \\
\hline Experience & & & 0.123 & $(0.011)$ & 0.123 & $(0.011)$ & 0.123 & $(0.011)$ & 0.123 \\
\hline Reputation & & & -0.032 & $(0.008)$ & -0.032 & $(0.008)$ & -0.032 & $(0.008)$ & -0.032 \\
\hline Skills & & & 0.011 & $(0.003)$ & 0.011 & $(0.003)$ & 0.011 & $(0.003)$ & 0.011 \\
\hline $\begin{array}{l}\text { Time } \\
\text { difference }\end{array}$ & & & & & 0.001 & $(0.013)$ & 0.005 & $(0.013)$ & 0.015 \\
\hline $\begin{array}{l}\text { Well- } \\
\text { known-ness }\end{array}$ & & & & & & & 0.354 & $(0.085)$ & 0.222 \\
\hline $\begin{array}{l}\text { Local wage } \\
\text { level }\end{array}$ & & & & & & & & & 0.223 \\
\hline $\begin{array}{l}\text { Random } \\
\text { effects }\end{array}$ & Var. & S.E. & Var. & S.E. & Var. & S.E. & Var. & S.E. & Var. \\
\hline $\begin{array}{l}\text { Country-level } \\
\mathrm{V}_{00 \mathrm{k}}\end{array}$ & 0.32 & $(0.57)$ & 0.33 & $(0.57)$ & 0.33 & $(0.58)$ & 0.13 & $(0.36)$ & 0.03 \\
\hline $\begin{array}{l}\text { Contractor- } \\
\text { level } U_{0 \mathrm{jk}}\end{array}$ & 0.49 & $(0.70)$ & 0.45 & $(0.67)$ & 0.45 & $(0.67)$ & 0.45 & $(0.67)$ & 0.45 \\
\hline $\begin{array}{l}\text { Project-level } \\
\mathrm{R}_{\mathrm{ij \textrm {k }}}\end{array}$ & 0.11 & $(0.34)$ & 0.12 & $(0.34)$ & 0.12 & $(0.34)$ & 0.12 & $(0.34)$ & 0.12 \\
\hline $\begin{array}{l}\text { Variance } \\
\text { explained }\end{array}$ & Prop. & & Prop. & & Prop. & & Prop. & & Prop. \\
\hline ICC & 0.35 & & 0.37 & & 0.37 & & 0.19 & & 0.05 \\
\hline Marginal $\mathrm{R}^{2}$ & 0.00 & & 0.05 & & 0.05 & & 0.34 & & 0.43 \\
\hline $\begin{array}{l}\text { Conditional } \\
\mathrm{R}^{2}\end{array}$ & 0.88 & & 0.88 & & 0.88 & & 0.89 & & 0.89 \\
\hline
\end{tabular}

\section{NOTE}

1. This research was supported by grants from the International Development Research Centre (107384-001) and the European Research Council (639652). 


\section{REFERENCES}

Arrow, K.J. 1998. What has economics to say about racial discrimination? Journal of Economic Perspectives, 12, 91-100.

Barrett, A., McGuinness, S., \& O’Brien, M. 2012. The immigrant earnings disadvantage across the earnings and skills distributions: The case of immigrants from the EU's new member states. British Journal of Industrial Relations, 50(3), 457-481.

Bracamonte, V., \& Okada, H. 2015. Is consumer perception of foreign online stores affected by the image of the country? An experimental study among Japanese consumers. Proceedings of ASE BD\&SI 2015, October 7-9, Kaohsiung, Taiwan. https:// dl.acm.org/doi/pdf/10.1145/2818869.2818923

Braesemann, F., Lehdonvirta, V., \& Kässi, O. 2020. ICTs and the urban-rural divide: Can online labour platforms bridge the gap? Information, Communication \& Society.

Choi, H., \& Varian, H. 2012. Predicting the present with Google Trends. The Economic Record, 88, 2-9.

Ciravegna, L., Lopez, L., \& Kundu, S. 2014. Country of origin and network effects on internationalization: A comparative study of SMEs from an emerging and developed economy. Journal of Business Research, 67, 916-923.

Fiske, S.T. 1998. Stereotyping, prejudice and discrimination. In Gilbert, D.T. \& Fiske, S.T. (Eds.) The Handbook of Social Psychology, Fourth Edition. Oxford: Oxford University Press.

Ghani, E., Kerr, W.R., \& Stanton, C. 2014. Diasporas and outsourcing: Evidence from oDesk and India. Management Science, 60(7), 1677-1697.

Graham, M., Hjorth, I., \& Lehdonvirta, V. 2017. Digital labour and development: Impacts of global digital labour platforms and the gig economy on worker livelihoods. Transfer: European Review of Labour and Research, 23, 135-162.

Horton, J. 2010. Online labor markets. In Internet and Network Economics: 6th International Workshop, Proceedings. Berlin: Springer, pp. 515-522. http://john -joseph-horton.com/papers/online_labor_markets.pdf

ILO. 2015. Global Wage Report 2014/15: Wages and income inequality. Geneva: International Labour Office.

Johansson, J.K., Douglas, S.P., \& Nonaka, I. 1985. Assessing the impact of country of origin on product evaluations: A new methodological perspective. Journal of Marketing Research, 22(4), 388-396.

Kässi, O., \& Lehdonvirta, V. 2018. Online Labour Index: Measuring the online gig economy for policy and research. Technological Forecasting and Social Change, 137, 241-248.

Koschate-Fischer, N., Diamantopoulos, A., \& Oldenkotte, K. 2012. Are consumers really willing to pay more for a favorable country image? A study of country-of-origin effects on willingness to pay. Journal of International Marketing, 20(1), 19-41.

Kuek, S.C., Paradi-Guilford, C., Fayomi, T., Imaizumi, S., Ipeirotis, P., Pina, P., \& Singh, M. 2015. The Global Opportunity in Online Outsourcing. Washington, DC: World Bank.

Laroche, M., Papadopoulos, N., Heslop, L.A., \& Mourali, M. 2005. The influence of country image structure on consumer evaluations of foreign products. International Marketing Review, 22(1), 96-115.

Lee, E.J. 2006. When and how does depersonalization increase conformity to group norms in computer-mediated communication? Communication Research, 33(6), 423-447. 
Lehdonvirta, V. 2018. Flexibility in the gig economy: Managing time on three online piecework platforms. New Technology, Work \& Employment, 33(1), 13-29.

Lehdonvirta, V., Kässi, O., Hjorth, I., Barnard, H., \& Graham, M. 2019. The global platform economy: A new offshoring institution enabling emerging-economy microproviders. Journal of Management, 45(2), 567-599.

Lippman, S.A., \& McCall, J.J. 1976. The economics of job search: A survey. Economic Inquiry, 14(2), 155-189.

Maheswaran, D. 1994. Country of origin as a stereotype: Effects of consumer expertise and attribute strength on product evaluations. Journal of Consumer Research, 21, 354-365.

Manning, A. 2011. Imperfect competition in the labor market. In Handbook of Labor Economics, Vol. 4. Elsevier, pp. 973-1041.

Musteen, M., Datta, D.K., \& Butts, M.M. 2014. Do international networks and foreign market knowledge facilitate SME internationalization? Evidence from the Czech Republic. Entrepreneurship Theory and Practice, 38, 749-774.

Nakagawa, S., \& Schielzeth, H. 2013. A general and simple method for obtaining $\mathrm{R}^{2}$ from generalized linear mixed-effects models. Methods in Ecology and Evolution, 4(2), 133-142.

Oostendorp, R.H. 2012. The Occupational Wages around the World (OWW) database: Update for 1983-2008. World Development Report 2013 Background Paper. Washington, DC: World Bank.

Pant, A., \& Ramachandran, J. 2012. Legitimacy beyond borders: Indian software services firms in the United States, 1984 to 2004. Global Strategy Journal, 2(3), 224-243.

Postmes, T., Spears, R., \& Lea, M. 1998. Breaching or building social boundaries? SIDE-effects of computer-mediated communication. Communication Research, 25(6), 689-715.

Preis, T., Moat, H.S., \& Stanley, H.E. 2013. Quantifying trading behavior in financial markets using Google Trends. Scientific Reports, 3, 1684.

Ramachandran, J., \& Pant, A. 2010. The liabilities of origin: An emerging economy perspective on the costs of doing business abroad. In Devinney, T.M., Pedersen, T., \& Tihanyi, L. (Eds.) Advances in International Management, Vol. 23. Bingley, UK: Emerald, pp. 231-256.

Shimp, T.A., Samiee, S., \& Madden, T.J. (1993). Countries and their products, a cognitive structure perspective. Journal of the Academy of Marketing Science, 21(4), 323-330.

Snijders, T., \& Bosker, R. 1999. Multilevel Analysis. London: Sage.

Solé, C., \& Parella, S. 2003. The labor market and racial discrimination in Spain. Journal of Ethnic and Migration Studies, 29(1), 121-140.

Spears, R., \& Postmes, T. 2015. Group identity, social influence, and collective action online. In Sundar, S.S. (ed.) The Handbook of the Psychology of Communication Technology. Chichester, UK: John Wiley \& Sons, pp. 23-46.

Stephens-Davidowitz, S. 2014. The cost of racial animus on a black candidate: Evidence using Google search data. Journal of Public Economics, 118, 26-40.

Tversky, A., \& Kahneman, D. 1974. Judgment under uncertainty: Heuristics and biases. Science, 185(4157), 1124-1131.

UNDP (United Nations Development Programme) (2015). Human Development Report 2015: Work for Human Development. New York: United Nations.

Verlegh, P.W.J., \& Steenkamp, J.-B.E.M. 1999. A review and meta-analysis of country-of-origin research. Journal of Economic Psychology, 20(5), 521-546. 
Wood, A.J., Lehdonvirta, V., \& Graham, M. 2018. Workers of the Internet unite? Online freelancer organisation in six Asian and African countries. New Technology, Work and Employment, 33(2), 95-112.

Wood, A.J., Graham, M., Lehdonvirta, V., \& Hjorth, I. 2019. Good gig, bad gig: Autonomy and algorithmic control in the global gig economy. Work, Employment and Society, 33(1), 56-75. 